\title{
IMAGE RIGHTS, CREATIVITY AND VIDEOGAMES
}

\author{
Dr Gaetano Dimita, ${ }^{1}$ Andrea Rizzi, ${ }^{2}$ Nicoletta Serao ${ }^{3}$
}

\section{CELEBRITIES AND VIDEOGAMES}

Videogames characters and avatars have been inspired by real people for decades, but now, technology and hyperrealism have increased the creative potential and consequentially the artistic and economic value of image rights ${ }^{4}$, thus creating new opportunities for celebrities to monetize image rights through licensing.

The link between the videogame character and the real person from whom the developers have drawn inspiration may often not even be immediately recognisable, for instance, when only a few traits of the celebrity are reproduced and the level of decontextualization of the avatar is significant: it is hard to see Theodore Roosevelt behind Mr. Robotic, the arch enemy of Sonic, the iconic SEGA hedgehog, even in its most realistically designed version ${ }^{5}$. Conversely, in other instances, developers might aim for the avatar to be easily and immediately linked to the celebrity, and this may, and often does, serve a specific creative purpose.

The inclusion of a celebrity in a videogame may be intended to generate greater involvement and players' participation ${ }^{6}$, or to manifest endorsement and promote the game. For instance, the presence of Kevin Spacey as a villain in Call of Duty: Advanced Warfare, while not being necessary for narrative reasons, attracted the public's attention in very much the same way as the presence of Cristiano Ronaldo on the cover of FIFA served to promote the game within his supporters and followers.

Using images of real people may in some instances serve a parody purpose. A character might be a caricature of a persona that may be seen as representing a certain group culture. In World of Warcraft you might come across the archaeologist Harrison Jones, which combines Harrison Ford traits with the very essence of Indiana Jones, and the blood elf vendor "Haris Pilton" accompanied by her inseparable pet Tinkerbell. Beyond the examples of cameos, videogames can also be entirely created for political parody such as the third person shooter Rise of Trump, where players help winning the presidency an orange tanned Donald Trump endowed with small hands, by gunning down his political enemies and convincing moustached Mexicans to pay for the wall. Similarly, several popular mobile games allow users to relax by punching and slapping Donald Trump, Ted Cruz and several other political figures. These videogames are - obviously - not endorsed by the political figures they are referring to.

\footnotetext{
${ }^{1}$ Senior Lecturer in International Intellectual Property Law, Centre for Commercial Law Studies, Queen Mary University of London.

${ }^{2}$ Partner, head of Interactive Entertainment, Digital Media \& Technology at Insight Studio Legale, Milan; Adjunct Professor, Media Law, Link Campus University, Rome; Visiting Lecture, Interactive Entertainment Law, Queen Mary University of London.

${ }^{3}$ Associate, Interactive Entertainment, Digital Media \& Technology at Insight Studio Legale, Milan.

${ }^{4}$ In this paper "image rights" refer to what globally is also made reference to as "personality rights" or "rights of publicity". The term right of publicity is used here only when specifically referring to image rights in a US law context. ${ }^{5}$ A caricature of Theodore Roosevelt dressed in a pyjamas was among the proposed designs that seems to have inspired the character of Dr. Ivo Robotnik.

${ }^{6}$ References to a celebrity embodying certain pop culture values establishes a connection between the player and something that the user is already familiar with.
} 
Last but not least, in sports games the use of athletes' images is crucial as this genre relies heavily on realistic representations of existing sports figures ${ }^{7}$ and of the arenas hosting the events (including spectators). Similarly, war games with historical settings may need to reproduce historical figures in order to make the historic setting more convincing and accurate.

The inclusion, within a videogame, of an avatar which faithfully reproduces a real person has value for a number of actors operating within the videogame industry, from the developers and publishers to the players themselves. However, a person has in principle a right to control the reproduction of its image and this right often causes tensions. However, in the absence of international treaties and harmonized rules on image rights, the specific way in which these rights have been acknowledged and developed may, and often does, vary significantly from country to country. This should come as no surprise since the right to control one's individual image is closely tied to a country's fundamental rights.

Indeed, in different jurisdictions the law admits, to varying extents, to individuals a certain degree of control over their name, photo, likeness, signature, and so on ${ }^{8}$. Under certain circumstances, an individual is legally entitled to license their image rights to a third party, but never to the point of depriving the image rights' holder of the right of using their own image.

Differences in respect of the legal status of image rights between national laws affect videogames in particular, because digital games often have a global reach and are distributed in tens of countries worldwide, which may trigger the application of the national laws of all the countries in which the game content is made available.

The result is that identifying, and considering, all potentially applicable national law rules, exceptions and limitations when clearing image rights for videogame use, may turn into a time-consuming legal conundrum. More specifically, whenever the use of an image is a means for an author to exercise their freedom of speech and expression, it is necessary to strike a balance between this fundamental right and the conflicting image rights. However, given the absence of clear and internationally recognised rules or principles on how this conflict should be resolved, this is an area where managing risks associated with the distribution of game content is no easy task, which may lead developers and publishers to take a risk adverse approach at the expenses of freedom of expression and creativity.

\section{THE P.E.M. (Prevalent, Exploitative, Misleading) TEST}

The United States ${ }^{9}$ case law has developed several different tests in order to identify the balance point between the right of publicity and the right contained in the First Amendment to the US

\footnotetext{
${ }^{7}$ They generally aim to mimics with the utmost realism the looks and movements of the real-life athlete.

${ }^{8}$ The protection afforded to image rights usually extends to the name, likeness, image, picture, voice and identity of the rights-holder, all of which are generally identified with the umbrella-term "persona".

Few countries provide a clear definition of image rights accompanied by a list of the specific features protected as part of one's persona (e.g. Canada and some states in the United States). Indeed, statutory provisions generally provide in very general terms that a person's image may not be reproduced without their consent (e.g. Italy and Germany) or give a nonexhaustive list of the protected features (e.g. France).

${ }^{9}$ The United States provide no federal law governing the right of publicity, on the contrary, the recognition of the right of publicity varies from state to state and each state determines the parameters of recognition. Furthermore, different judicial districts within the United States have developed different tests to determine the scope and application of the right of publicity as against the First Amendment right.
} 
Constitution ${ }^{10}$. These tests are: the transformative use test, which focuses on the degree of creative transformation of the image ${ }^{11}$; the predominant use test, which considers whether the purpose of the work is predominantly commercial or expressive ${ }^{12}$ and the relatedness test (or so-called "Rogers test"13), concentrating on the question of whether or not the image is wholly unrelated with the work where is reproduced and, consequently, consumers may be explicitly misled into believing that celebrities are endorsing the reproduction of their images ${ }^{14}$.

10 The First Amendment to the United States Constitution provides that «Congress shall make no law respecting an establishment of religion, or prohibiting the free exercise thereof; or abridging the freedom of speech, or of the press; or the right of the people peaceably to assemble, and to petition the Government for a redress of grievances».

${ }^{11}$ The transformative use test was first formulated in Comedy III Productions, Inc. v Gary Saderup, Inc., 25 Cal. 4th 387 , 106 (Cal., 2001) and was derived from copyright's fair use exception, to the extent that it was compatible with the right of publicity. As there referred by the Supreme Court, the test should be understood to be «a balancing test between the First Amendment and the right of publicity based on whether the work in question adds significant creative elements so as to be transformed into something more than a mere celebrity likeness or imitation». In the same ruling the Supreme Court found that «when a work contains significant transformative elements, it is not only especially worthy of First Amendment protection, but it is also less likely to interfere with the economic interest protected by the right of publicity». The transformative use test has the virtue of providing courts with a flexible and analytical framework that allows to balance the First Amendment with publicity rights, without unnecessarily frustrating the freedom of expression of the work. As intended by the Third Circuit Court of Appeals in Hart v Electronic Arts, Inc., 717 F.3d 141 (3rd Cir. 2013), this test limits the «right of publicity claims to a very narrow universe of expressive works».

On the other hand, as pointed out by D Georgescu in 'Two Tests Unite to Resolve the Tension Between the First Amendment and the Right of Publicity' (2014) 83, Fordham L. Rev., 907 and MD Bunker and C Calvert, 'Video Games and the right of Publicity: the Courts drop the Ball', (2016) 93(3), J MASS COMMUN Q, 627, the flexibility provided by the transformative use test carries some risks. In general, since this test only provides broad categories of factors to be weighed in, the result of the test is quite unpredictable. Moreover, given that there is no clear definition of what should be intended as transformative, the courts are called on to make a judgement based on the merit of the work, more than on the law itself, thus increasing the risk of having conflicting decisions in similar cases.

12 The predominant use test was introduced by the Supreme Court and is intended to apply to cases where the work is both of a commercial and expressive nature. In particular, in John Doe v. TCI Cablevision, 110 S.W.3d 363, 373 (Mo. 2003), a case regarding the NHL player Anthony "Tony" Twist and the comic book Spawn featuring a certain character named Antonio Twistelli, nicknamed Tony Twist, the Supreme Court stated that «if a product is being sold that predominantly exploits the commercial value of an individual's identity, that product should be held to violate the right of publicity and not be protected by the First Amendment».

This allowed the Court to sanction a use that was partly creative - and therefore likely to satisfy a transformative use test. However, as it is noticed in M H Redish and K B Shust, 'The Right of Publicity and the First Amendment in the Modern Age of Commercial Speech', (2015) 56 Wm. \& Mary L. Rev. 1443, it has the clear downside of focusing only on profit, without leaving any room for First Amendment protection whenever the use of the image is (even partially) commercial. ${ }^{13}$ The relatedness test (or Rogers test) originated in the context of Ginger Rogers v Alberto Grimaldi, et al, 875 F.2d 994 (2d Cir. 1989), a lawsuit which concerned the right of publicity of Ginger Rogers and Fred Astaire, whose first names were mentioned in the title of the Federico Fellini's movie "Ginger and Fred".

The test extended to publicity right claims the same reasoning used in relation to trademark violations under the Lanham Act. Using this test the Court reached the conclusion that the use of a celebrity's name in a movie title should not be barred unless the title was «wholly unrelated» to the movie or was «simply a disguised commercial advertisement for the sale of goods or services».

The Rogers test evaluates the relationship between the image and the alleged reproduction of the image, and it does so by considering the work of art as a whole, instead of merely looking at the use of the image per se.

${ }^{14}$ Moreover, in Cardtoons, L.C. v. Major League Baseball Players Ass'n, 95 F.3d 959 (10th Cir. 1996), the Tenth Circuit applied a fourth balancing test, which is known as the ad-hoc balancing test. This test highlights that courts, when establishing whether a reproduction of a certain celebrity's image infringes the celebrity's image rights, should take into account the importance that image rights and freedom of expression have in the case at hand, both for the parties of the proceeding and for the society at large. However, this test does not seem to constitute per se an alternative test, insomuch as it does not introduce any (new) specific criterion to be relied on for the purposes of making the assessment. Unsurprisingly, the ad-hoc test was applied in conjunction with the transformative use test by the Sixth Circuit in ETW Corp. v. Jireh Publishing Inc., 332 F.3d 915 (6th Cir. 2003). On the desirability of combining the transformative test with the ad-hoc test see also D Georgescu in 'Two Tests Unite to Resolve the Tension Between the First Amendment and the Right of Publicity’ (2014) 83, Fordham L. Rev., 907. 
Each of these tests focus on different, and yet all relevant, aspects of the relation between the image and the work featuring that image. If considered on their own, these tests present meaningful limits and may lead to very different, and therefore often unpredictable, results, which in turn creates uncertainty around what should constitute a sanctionable image rights' violation, and what shouldn't ${ }^{15}$.

We argue that all three tests fail to provide clear enough guidance to the legal practitioner advising the developers team on the risks associated with their work as the creative team has imagined it and that their application may lead to different results according to the judges thus making an analysis, let alone a global analysis, impractical and consequently are only of limited practical use.

Therefore, in an attempt find the synthesis between the different approaches available under US case law, which is the most developed law on the topic of image rights, creativity and videogames, we have tried to combine them with a view to suggesting a more precise path to assess the level of risk associated with using, without authorisation, a real-life person's image in a videogame. The three prongs we suggest are:

1. Are the imitative elements of the real-life person image prevalent vis-à-vis - the creative elements of the character?

2. Is the use exploitative?

3. Is the use misleading ? $^{16}$

We regard the profound differences that still exist at country-national level in respect of how videogames are perceived in society depending on local culture as a potential weakness in respect of the possibility that the test we suggest may work internationally. This is because the question, which is cultural in nature, whether videogames should be recognised as a form of artistic expression and, therefore, be treated with the same dignity as and on a par with other, more established and therefore more widely accepted, artistic expressions like filmmaking, painting, photography, etc., does not receive a uniform answer in all jurisdictions.

Therefore, before we turn to discuss how each of the three prongs above may work in the context of assessing when the developers' right to free speech and expression should out-weight a real person's image rights, let us be straight on this fundamental point: videogames are creative works and should enjoy full freedom of speech protection.

\footnotetext{
15 This is also due the significant degree of subjectivity that is intrinsic to all of these tests.

${ }^{16}$ It seems that regardless of the creativity in the use of the image, and quite independently from the predominance and the commercial or expressive nature of the work where the image is used, whenever the work gives the impression that the image rights' holder has endorsed the use, the image rights infringement claim should prevail over the freedom of speech defence.

This reasoning is in line with the nature of the right of publicity as described by the United States Supreme Court in Zacchini v. Scripps Scripps-Howard Broadcasting Co., 433 U.S. 562 (1977) «[t]he rationale for protecting the right of publicity is the straightforward one of preventing unjust enrichment by the theft of goodwill. No social purpose is served by having the defendant get free some aspect of the plaintiff that would have market value and for which he would normally pay».

It appears that a similar argument could also be used in countries where image rights are not expressly recognised to argue that the unauthorized use of a celebrity's image should constitute passing off. This was the case in the UK with Topshop t-shirts with Rihanna's face on in Fenty \& Ors v Arcadia Group Brands Ltd (t/a Topshop) \& Another [2013] EWHC 2310 (Ch). In particular, the judge although stressing that «the mere sale by a trader of a t-shirt bearing an image of a famous person is not, without more, an act of passing off» considered that, in the case at issue, a substantial portion of consumers considered that the use had been authorized by the pop star and therefore constituted passing off.
} 
Videogames collections and exhibitions are now present at the Smithsonian American Art Museum, the New York MOMA, the V\&A in London ${ }^{17}$. However, the recognition of videogames as a form of art has long been met with reservations. Some art critics, such as the late film critic Roger Ebert ${ }^{18}$, were reluctant to accept the artistic nature of videogames ${ }^{19}$ and are still prudent when conceding that a certain videogame or certain elements of videogames ${ }^{20}$ are works of art. The majority, however, finds increasingly difficult to deny in principle the artistic value of videogames, though taking the view that the 'art' label should only be reserve to few "masterpieces" 21.

Leaving the art world debate aside, the crucial point is the recognition that videogames have received by courts of law and how their artistic recognition might influence the balancing of conflicting rights. Courts and legislators - similarly to art critics - struggled to recognize the artistic value of the videogame as a medium ${ }^{22}$ and videogames as comprehensive works of art were recognized for the first time in 2011's Brown v. Entertainment Merchants Association when Judge Scalia held that:

Like the protected books, plays, and movies that preceded them, videogames communicate ideas - and even social messages - through many familiar literary devices (such as characters, dialogue, plot, and music) and through features distinctive to the medium (such as the player's interaction with the virtual world). That suffices to confer First Amendment protection. Under our Constitution, "aesthetic and moral judgments about art and literature ... are for the individual to make, not for the Government to decree, even with the mandate or approval of a majority". ${ }^{23}$

As a general principle, with a view to encouraging and promoting artistic creations, the limitation of an artist's freedom of expression should be kept to a minimum. Consequently, the artistic recognition of videogames, we argue, should meaningfully affect the balancing of conflicting rights and whenever a person's image is reproduced within the context of a videogame with some artistic value, that value should proportionally move the balance point to the developers' $\operatorname{side}^{24}$ allowing them a greater room for fair use of a third party's image rights ${ }^{25}$.

${ }^{17}$ See S Romualdo, 'Curating the Arcade: Strategies for The Exhibition Of Videogames'(2017) 2, in International Journal
of Film And Media Arts, 24 .
${ }^{18}$ See R Ebert, 'Video games can never be art' < https://www.rogerebert.com/rogers-journal/video-games-can-never-be-
$\frac{\text { art }>\text { accessed on } 15 \text { September } 2019 .}{19}$ See J Jones, 'Sorry MoMA, video games are not art' <https://www.theguardian.com/artanddesign/jonathanjonesblog/2012/nov/30/moma-video-games-art>, accessed on 15 September 2019.

${ }^{20}$ See B Sherwin, 'Video Games as Art: The debate continues'<http://theartedge.faso.com/blog/86199/video-games-asart-the-debate-continues>, accessed on 15 September 2019.

See A 'Are Smuts, Video Games Art?' <https://www.contempaesthetics.org/newvolume/pages/article.php?articleID=299>, accessed on 15 September 2019.

${ }^{22}$ In 2002 the US District Court for the Eastern District of Missouri in Interactive Dig. Software v St. Louis County, Mo., 200 F. Supp. 2d 1126 (E.D. Mo. 2002), held that videogames are not speech stating that «[t]his Court reviewed four different videogames, and found no conveyance of ideas, expression, or anything else that could possibly amount to speech. The Court finds that videogames have more in common with board games and sports than they do with motion pictures. A few courts have looked at whether "Bingo" is speech and protected under the First Amendment. In this instance, the Seventh Circuit held that "Bingo" does not convey ideas, nor does it contain "expression"».

${ }^{23}$ See Brown v Entertainment Merchants Association, 564 U.S. 786 (2011).

${ }^{24}$ As referred to in C Coors, 'Celebrity image rights versus public interest: striking the right balance under German law', (2014) 9, in JIPLP, 835, in the German case Düsseldorf Higher Regional Court, 23 July 2013, I-20 U 190/12, regarding unauthorized portraits of the golf player Martin Kaymer, the Court - while denying that the claimant's portrait reproducing the athlete, should fall under the protection afforded by the freedom of the art principle provided in Article 5(3) of the German Basic Law - recognized that, in principle, «the manipulation of a photo of a celebrity is a creative art form in itself that requires skill and precision» and that «the style, quality level and content of the art can play a role in the assessment of whether artistic freedom must yield to conflicting constitutional interests».

25 See, inter alia, City of Cincinnati v Discovery Network, Inc., 507 U.S. 410, 423, 113 S.Ct. 1505, 123 L.Ed.2d 99 (1993). 
When the sport artist Jireh used Tiger Wood's image as the main subject of one of his paintings, the Court found that there was no false endorsement, also in light of the artistic value of the painting at issue, providing that «when an artist adds significant expressions then the artist enjoys First Amendment Protection for his work» ${ }^{26}$.

It should follow that whenever a videogame character clearly refers to a certain celebrity and does not seems to be particularly transformative, the artistic value of the videogame and the functional link between the character and the narrative should become crucial in assessing whether or not an unauthorized use of a celebrity's image was legitimate.

However, despite the observed trends within American case law, judges worldwide are not often assessing whether the videogame at issue should be considered an art piece ${ }^{27}$ which means that the relevance of the artistic value of the videogame still remains largely disregarded.

\section{Prevalent imitative use}

Since videogames are art and this is why they in principle attract First Amendment protection in the US and given that characters carry significant creative weight within a videogame as key literary devices, then the artistic value of a videogame character, on the one hand, has an important impact on the overall creativity of a game whilst, on the other hand, it should be a factor per se capable of resolving a conflict between the right of an individual to control their image and the right to free speech.

Sometimes the developers draw inspiration from one or more real life personas to create an original virtual character with its own features. Think of Lara Croft or $\mathrm{Kratos}^{28}$. The archaeologist protagonist of Tomb Raider was inspired by real life celebrities, yet probably no one would say who they were without more precise indications from the developers and this is because, while the videogame character could remind the observer of someone the latter may know, Lara Croft individual features outweigh the imitative ones and are those that the observer would recognise and appreciate the most ${ }^{29}$. Characters like Lara should, and most probably would, be regarded as original according to any test in any jurisdiction. The use of a third party's image here is highly transformative because the character is highly creative. Likeness with a celebrity, if any could be spotted, is not relevant to the game being sold and it would seem very unlikely that consumers could be misled into believing that a certain celebrity is somehow affiliated with the game. Moreover, while the purpose of the work is, undoubtedly, predominantly commercial, the use of the celebrity's image within the game is not, regardless of the predominance of the character itself.

Generally speaking, whenever the character bears a considerable degree of originality and creativeness, the restriction of the freedom of expression of the developer in view of the image rights

\footnotetext{
${ }^{26}$ See Etw Corporation v Jireh Publishing, Inc., 332 F.3d 915 (6th Cir. 2003).

${ }^{27}$ For instance, see Hamburg Higher Regional Court, 13 January 2003, 7 U 41/03 and TJSP, proceeding no. 1126481 26.2016.8.26.0100, Judge Rodrigo Cesar Fernandes Marinho, decided on 27 August 2017, where respectively, German and the Brazilian Courts are not addressing the issue of whether videogames are qualified for protection by freedom of expression.

${ }^{28}$ Kratos is the main character of the videogame saga God of War, he is a Spartan hero with the troubled past of a Greek God. The designer of Kratos revealed that he took inspiration from Edward Norton playing a nazi in the movie American History X, see Zak Islam, 'Jaffe Reveals Inspiration Behind Kratos' <https://www.playstationlifestyle.net/2010/07/22/jaffe-reveals-inspiration-behind-kratos/> accessed on 15 September 2019.

${ }^{29}$ In fact, the celebrities inspiring Lara Croft changed over time without players really noticing it. Lara was initially inspired (also) by the Swedish singer Neneh Cherry, then played by several actress, including Keeley Hawes, Jonell Elliott and others and most recently by Camilla Luddington in the Survivor Timeline.
} 
of the real-life personas (which somehow inspired that creation) should be considered in principle unjust.

Sometimes, however, videogame characters are not strong, unique heroines and heroes like Lara Croft or Kratos. Sometimes the character is meant to be a stereotype of a certain pop culture, a certain generation or social background. The features of the character are therefore pop culture condensations, rather than distinctive and unique characteristics traceable back to a certain real-life person. Here, the character probably suggests only some connection with whomever is considered a stereotype of that same group in real life or in connection with other forms of art. Of course, people who based their commercial success on being exactly that stereotype might recognize themselves in such videogame characters, and so might do the public at large.

Lacey Jonas and Antonia Bottino, two minor characters in Grand Theft Auto V, were surely incorporating two different stereotypes: the image of an obsessed anorexic teen actress-slash-singer and the Italian American mob boss's daughter. Lindsay Lohan and Karen Gravano, finding that the characters of Lacey and Antonia were based on them, brought claims against the videogame publisher Take-Two Interactive Software, alleging a violation of their publicity right.

Both lawsuits were finally tossed out by a 6-0 vote of the New York State's highest Court ${ }^{30}$, which, with specific regard to the claim regarding the Lacey Jonas character found that the character was lacking a physical resemblance with Lohan and that «the ambiguous representations in question are nothing more than cultural comment that is not recognizable as plaintiff and therefore is not actionable» ${ }^{31}$. According to the Court «the Jonas character simply is not recognizable as plaintiff inasmuch as it merely is a generic artistic depiction of a "twenty something" woman without any particular identifying physical characteristics ${ }^{32}$, therefore confirming that the right of publicity will not cover those personality traits that are not distinctive of a certain specific character.

Prior to Lohan's and Gravano's lawsuits, even the singer and fashion icon Kierin Kirby tried (and failed) to demonstrate that a videogame character was created in violation of her image rights ${ }^{33}$. The character in question was Ulala, protagonist of Space Channel 5, a videogame published by Sega of America, Inc.

Ulala's similarity to Kirby was probably stronger than that of Lacey Jonas and Antonia Bottino with Lohan and Gravano ${ }^{34}$; furthermore, Sega had also somehow declared its intent to use Kierin Kirby as an inspiration for one of its characters, by asking Kirby for a license on her image rights, which she refused to grant. Nonetheless, the character was found to be transformative enough to deserve protection under the First Amendment. What contributed to this ruling was that, similarly to Grand Theft Auto V's characters, Ulala was actually based on a certain style, namely the Japanese style of "Anime", more than on a specific celebrity and, therefore, the virtual character was not solely referring to Kirby.

These cases seem to confirm that the actual scope of image rights may not be broad enough to include also those characteristics which are - or became - typical of a certain stereotype, more than of a specific character.

\footnotetext{
${ }^{30}$ See Lohan v Take-Two Interactive Software, Inc. 92 N.E.3d 807 (N.Y. 2018) to which Gravano v Take-Two Interactive Software, Inc. N.Y. Slip Op. 60748 (N.Y. 2018) is referring in turn.

${ }^{31}$ Ibidem.

32 Ibidem.

${ }^{33}$ See Kirby v. Sega of America, Inc., 144 Cal. App. 4th 47 (2006).

${ }^{34}$ In Kirby v. Sega of America, Inc., Kierin Kirby claimed that the defendant copied «her "unique public identity," which combines retro and futuristic visual and musical styles, results from her signature costumes and lyrical expression» in Ibidem.
} 
However, in these cases the plaintiffs were not able to demonstrate a real physical resemblance between themselves and the characters, and that the characters' names were significantly different. Indeed, the outcome of the lawsuits may well have been very different if there had been a physical resemblance and / or the names of the characters had recalled the names of the celebrities.

A very similar name, together with a strong physical resemblance was that of Ellie, the 14-year-old protagonist of the game The Last of Us, with the actress Ellen Page. Here, the degree of physical similarities (especially in the first videogame trailer ${ }^{35}$ ), the assonance between the names and the fact that the Canadian actress was interpreting another videogame's character at the time The Last of Us was released, could have been an argument for establishing that the use was imitative and exploitative. Ellen Page never brought claims against it as the actress simply criticized the developers for 'ripping off her likeness ${ }^{36}$ when designing the character Ellie.

\section{Exploitative use}

If the degree of similarity between the real person and the image as reproduced in game plays an important role in the analysis, this is not to say that there cannot be imitative uses that may be legitimate even without the celebrity's authorization, provided that exploiting the real person's image is not evidently the sole reason of the use.

In more practical terms this means that the reproduction should have a primary artistic and not exploitative purpose and that the use of that image should be consistent and proportionate to its artistic role within the videogame. Parody is one example.

The online game Moshi Monsters developed by the British entertainment company Mind Candy featured a character named Lady Goo Goo, a toddler singer with platinum blonde hair and big sunglasses. The character appeared as a caricature of the artist Lady Gaga but bearing a significant transformation and quite a clear parodying intent. However, while, English law provides the possibility of a common law action for passing off whenever the reproduction constitutes false endorsement, the UK does not have any specific law on image rights per $\mathrm{se}^{37}$, which, considering the parody intent of the reproduction in question, would have made it hard to argue that Lady Goo Goo was unlawfully reproducing Lady Gaga's features ${ }^{38}$. However, Lady Gaga was not only the nickname of Ms Germanotta, but also a trademark, and Mind Candy was indeed sued for trademark infringement ${ }^{39}$. The fact that English trademark law does not provide for a parody defence ${ }^{40}$ led the English High Court of Justice to rule in favour of the plaintiff giving us little indication on what could be the scope of parody in relation to the unauthorized use of celebrities' images.

\footnotetext{
35 The character was redesigned before the release of the videogame to resemble more like Ashley Johnson, the actress that was actually playing Ellie, thus in its latest version the character resembled less Ellen Page.

36 See Erik Kain, 'Ellen Page Says Naughty Dog 'Ripped Off' Her Likeness For The Last Of Us' <https://www.forbes.com/sites/erikkain/2013/06/24/ellen-page-says-naughty-dog-ripped-off-her-likeness-for-the-lastof-us/\#43788bcc3f2e> accessed on 15 September 2019.

${ }^{37}$ As the Court of Appeal provided in Fenty \& Ors v Arcadia Group Brands Ltd (t/a Topshop) \& Another [2013] EWHC $2310(\mathrm{Ch})$ «There is in English law no "image right" or "character right" which allows a celebrity to control the use of his or her name or image».

${ }^{38}$ See also footnote 16 above in relation to the possibility of arguing passing off in similar cases.

${ }^{39}$ Ate My Heart Inc v Mind Candy Ltd [2011] EWHC 2741 (Ch).

${ }^{40}$ However, recital 27 of the Parliament and Council Directive (EU) 2015/2436 of 16 December 2015 and recital 21 of the Parliament and Council Regulation (EU) 2015/2424 of 16 December 2015, both passed after the ruling in this case, while not providing an explicit parody exception in relation to trademark infringement, make reference to fair use of trademark for the purpose of artistic expression and provide that the piece of legislation should be applied in a way that ensures full respect for freedom of expression.
} 
Of course, the parodying intent often requires - in order to be effective - a unique reference to a certain public figure and, moreover, obtaining a license on the use is usually not an option.

One could argue that certain public figures lose some control over their image because they lose control over the historic character they come to embody. This could apply to famous artists also but has a greater relevance when dealing with politicians and in general with historical characters. On the other hand, freedom of expression in a democratic society calls for enhanced protection in respect of all political criticism.

Subject to the limit that public figures should not be portrayed in a way that would unjustly harm the honour, reputation or decorum of the person being portrayed, the scope of the right of parody in relation to politicians would largely depend on the specific jurisdiction we are in and, in that regard, it is difficult to find some common ground.

In general, whenever a public figure is reproduced for the purpose of political criticism or that of leveraging on historic realism of the videogame, the reputation of the public figure, the artistic value of the game and the proportionality of the use of the image that is made within the game are all elements that should be taken into account when assessing whether or not the use is exploitative.

For instance, the reputation of a certain public figure may narrow the scope of protection of their image rights. This could have happened, for instance, to the Panamanian dictator Manuel Noriega.

Activision featured a character in Call of Duty: Black Ops II which was named after the dictator (although you may recall him by the nickname "pineapple face") and had his physical features. Noriega, from jail, claimed that his image rights were violated as the character's aspect was replicating exactly his image. However, the Court stated that the use of Noriega's image was legitimate after applying the transformative test ${ }^{41}$. Some scholars argued, not without merit, that Noriega did not have a publicity right to start with because he had no right to profit from the exploitation of his image, since his celebrity depended mostly on the infamous action he committed and, therefore, that the Court should not have applied the transformative use test, because doing so, it suggested that Noriega has some rights of exploiting his image ${ }^{42}$.

Applying a similar reasoning in a reversed situation, also the underlaying message of the videogame as a whole - more than the character itself - should be relevant. This is the case of the French videogame "Jean-Marie, jeu national multimedia", developed by Philippe Le Gallou - member of the right-wing extremist party Front National - which featured a character that reproduced the president of the association SOS Racisme (Fodé Sylla) as one of the "enemies of France" who Jean-Marie Le Pen would have to defeat in order to reach the Elysée.

The videogame's character was found to be in violation of Fodé Sylla's image rights and, also in consideration of the political scope of the game ${ }^{43}$, the freedom of expression-based defences did not

\footnotetext{
${ }^{41}$ Manuel Noriega v. Activision Blizzard, Inc., No. BC 551747 (Cal Super. Ct. 2014)

${ }^{4}$ See J Sinclair, 'Noriega v. Activision/Blizzard: The First Amendment Right to Use a Historical Figure's Likeness in Video Games', (2015) 14 Duke Law \& Technology Review 69-82 (2015). Sinclair's theory that celebrity's image rights should not be an absolute right, but instead should depend upon the celebrity's reputation, is convincing, especially because it fits perfectly with the doctrine which, perceiving the image as an asset, maintains that the image right's scope should be linked to the investments made in order to build a certain image. Understood in this way, celebrities would be rewarded not regardless in relation to their image but limiting to unique and somehow positive features.

${ }^{43}$ See ruling "jeu multimédia Front national 92", Cour d'appel de Versailles, 8 mars 1996, Gazette du Palais, 1 mai 1996.
} 
hold up in court. In fact, the character was found to be an unauthorized reproduction, created for political reasons and not with a parodying intent ${ }^{44}$.

Moreover, also whenever the balance point between the celebrity's image rights and the videogame developer freedom of expression tends towards the artist, the use of the reproduction in marketing material should be an indication that the use at hand may be exploitative.

\section{Misleading use}

There is still a question whether is safe to assume that a reproduction of an image without any original narrative or a parodistic value, but which is not exploitative of a certain celebrity's image, is lawful.

In order to answer this question, it is important to consider whether the public would assume that the image was reproduced under license.

This is evident with sports games' characters, which faithfully physically reproduce the athlete within a similar context without any original narrative or a parodistic value, but which are often a necessary videogame element whenever we deal with state-of-the-art sports games.

On the one hand, it is true that athletes invest a lot on the construction and maintenance of their image and some argue that because of this their images rights are afforded quite a strong protection ${ }^{45}$, also because the athletic career is limited in time and licensing revenues may be important support for some athletes at a later state. On the other hand, when developing a sports game, characters based on real-life athletes are essential to make the videogame realistic.

So far, most unauthorized uses of athletes' images were found by American Courts not to be protected under the First Amendment and when called to decide on a publicity right violation claim US judges have tended to apply the transformative use test ${ }^{46}$, by comparing the athlete's image with the character in itself - rather than considering the character within the videogame context as a whole. The result was that athletes' videogame avatars were rarely found to be transformative enough ${ }^{47}$ to justify the compression of the conflicting real person's image rights.

The appropriateness of the transformative use test - as it has been applied so $\operatorname{far}^{48}$ - has been heavily lamented. Some judges criticized the narrow application of the transformative use test and suggested

\footnotetext{
${ }^{44}$ Moreover, even though the ruling does not refer to it, the dubious content of the videogame - which was described as racist - may also played a part in the balancing between the developer's rights and the image rights of Fodé Sylla.

${ }^{45}$ Consistently with the doctrine which perceives the image as an asset referred also in M H Redish and K B Shust, 'The Right of Publicity and the First Amendment in the Modern Age of Commercial Speech', 56 Wm. \& Mary L. Rev. 1443 (2015), at least whenever a celebrity's image is at issue, image rights scope should be linked to the investments made by a given celebrity in order to make their personality unique.

${ }^{46}$ See Hart v Electronic Arts, Inc., 717 F.3d 141, 153, 160 (3d Cir. 2013), Keller v Electronic Arts, Inc. No. 10-15387, 2013 WL 3928293, *5 (9th Cir. 2013) and O'Bannon v. Nat'l Collegiate Athletic Ass'n, 7 F.Supp.3d 955 (N.D. Cal. 2014). An exception to this tendency was Brown v Electronic Arts, Inc., 724 F.3d 1235 (9th Cir. 2013) where the Court applied the Rogers test - instead of the transformative use test - and held that the use of Brown's likeness in Madden NFL games was protected by First Amendment, because it was artistically relevant to the games.

${ }^{47}$ In Hart v Electronic Arts, Inc., the $3^{\text {rd }}$ Circuit held that «the NCAA Football 2004, 2005 and 2006 games at issue in this case do not sufficiently transform Appellant's identity to escape the right of publicity claim».

${ }^{48}$ Courts, when applying the transformative use test, generally have compared the videogame character with the real person taking into consideration the player image, without considering the videogame character within the videogame context.
} 
the creative elements and the features of the videogame as a whole should be evaluated, rather than focusing on the avatar's degree of resemblance with the person's image ${ }^{49}$.

From a US perspective, the Rogers test instead of the transformative use test could lead to a fairer balance between image rights and freedom of speech and also ensure that videogame characters are not treated differently from other form of artistic portrayal ${ }^{50}$.

On the other hand, though any use of players' images is in principle relevant to a sports videogame, judges should avoid resorting to an interpretation of the scope of the First Amendment that legitimates that athletes' images may be included into sports videogames without the athletes receiving fair compensation.

Ultimately, the principle is that any reproduction that would represent false endorsement should be considered misleading and therefore an infringement.

\section{CONCLUSIONS}

There is clearly a trend, which we believe will continue in the future, towards licensing of image rights whenever a celebrity is due to be included in a videogame. This may be explained partly because a celebrity image license agreement is normally combined with a professional services agreement that ensure the active collaboration and engagement of the celebrity and partly because the national laws normally afford celebrities a significant degree of protection over their image. In parallel, we also see a new trend, with the United States leading the way, towards a stronger protection of the right to free speech and freedom of expression in connection with videogames based on the view that videogames may qualify as works of creative and artistic expression.

The lack of harmonized rules, however, and the different subtleties in image rights protection that are still to be found at national law level are all elements that generate uncertainty and contribute to the image rights clearance to be more a business decision than a regulatory compliance activity.

This produces inefficiencies as whenever it is not clear if the unauthorized use is lawful at a global level, the savvy business decision for the developer is to contractually regulate the third party's image use, which almost inevitably, though, will entail additional production costs.

This may have the de facto consequence of favouring the protection of image rights over free speech, even when a potentially legitimate unauthorized image right use is at issue.

Thus, in an attempt to suggest a more precise path to assess the level of risk associated with using, without authorisation, a real-life person's image in a videogame that may work internationally as a source of guidance for assessing the likelihood that the unauthorised use of a real person's image within a videogame may be legitimate, we suggest the relevant assessment is carried out taking into consideration the following:

\footnotetext{
49 Judge Ambro dissented in Hart v Electronic Arts, Inc., concluding that «the creative components of NCAA Football contain sufficient expressive transformation to merit First Amendment protection». Similarly, Judge Thomas in Keller $v$ Electronic Arts, Inc. held that «the creative and transformative elements of Electronic Arts' NCAA Football video game series predominate over the commercial use of the athletes' likenesses, the First Amendment protects EA from liability». Moreover, J. Thomas considered - in accordance with J. Ambro opinion in Hart, that «[t]he majority confines its inquiry to how a single athlete's likeness is represented in the video game, rather than examining the transformative and creative elements in the video game as a whole. In my view, this approach contradicts the holistic analysis required by the transformative use test».

${ }^{50}$ See MD Bunker and C Calvert, 'Video Games and the Right of Publicity: the Courts Drop the Ball', (2016) 93(3), Journalism Mass Commun. Q, 627.
} 
1) the artistic weight that the creative use of the virtual reproduction of a celebrity bears in respect of the specific videogame as an artistic work,

2) the possible exploitative intent behind the reproduction of a certain celebrity's image;

3) the eventuality that the public is misled into thinking that the reproduction was specifically authorized by the right holder,

and we have formulated a three prongs test - the P.E.M. test - to serve this specific purpose. 